\title{
Soil Infrastructure, Interfaces \& Translocation Processes in Inner Space ("Soil-it-is"): towards a road map for the constraints and crossroads of soil architecture and biophysical processes
}

\author{
L. W. de Jonge ${ }^{1}$, P. Moldrup ${ }^{2}$, and P. Schjønning ${ }^{1}$ \\ ${ }^{1}$ Aarhus University, Dept. of Agroecology and Environment, P.O. Box 50, 8830 Tjele, Denmark \\ ${ }^{2}$ Aalborg University, Dept. of Biotechnology, Chemistry and Environmental Engineering, Sohngaardsholmsvej 57, \\ 9000 Aalborg, Denmark
}

Received: 27 February 2009 - Published in Hydrol. Earth Syst. Sci. Discuss.: 25 March 2009

Revised: 7 August 2009 - Accepted: 12 August 2009 - Published: 19 August 2009

\begin{abstract}
Soil functions and their impact on health, economy, and the environment are evident at the macro scale but determined at the micro scale, based on interactions between soil micro-architecture and the transport and transformation processes occurring in the soil infrastructure comprising pore and particle networks and at their interfaces. Soil structure formation and its resilience to disturbance are highly dynamic features affected by management (energy input), moisture (matric potential), and solids composition and complexation (organic matter and clay interactions). In this paper we review and put into perspective preliminary results of the newly started research program "Soil-it-is" on functional soil architecture. To identify and quantify biophysical constraints on soil structure changes and resilience, we claim that new approaches are needed to better interpret processes and parameters measured at the bulk soil scale and their links to the seemingly chaotic soil inner space behavior at the micro scale. As a first step, we revisit the soil matrix (solids phase) and pore system (water and air phases), constituting the complementary and interactive networks of soil infrastructure. For a field-pair with contrasting soil management, we suggest new ways of data analysis on measured soil-gas transport parameters at different moisture conditions to evaluate controls of soil matrix and pore network formation. Results imply that some soils form sponge-like pore networks (mostly healthy soils in terms of agricultural and environmental functions), while other soils form pipe-like
\end{abstract}

Correspondence to: $\mathrm{L}$. W. de Jonge

(lis.w.de.jonge@agrsci.dk) structures (agriculturally poorly functioning soils), with the difference related to both complexation of organic matter and degradation of soil structure. The recently presented Dexter et al. (2008) threshold (ratio of clay to organic carbon of $10 \mathrm{~kg} \mathrm{~kg}^{-1}$ ) is found to be a promising constraint for a soil's ability to maintain or regenerate functional structure. Next, we show the Dexter et al. (2008) threshold may also apply to hydrological and physical-chemical interface phenomena including soil-water repellency and sorption of volatile organic vapors (gas-water-solids interfaces) as well as polycyclic aromatic hydrocarbons (water-solids interfaces). However, data for differently-managed soils imply that energy input, soilmoisture status, and vegetation (quality of eluded organic matter) may be equally important constraints together with the complexation and degradation of organic carbon in deciding functional soil architecture and interface processes. Finally, we envision a road map to soil inner space where we search for the main controls of particle and pore network changes and structure build-up and resilience at each crossroad of biophysical parameters, where, for example, complexation between organic matter and clay, and moistureinduced changes from hydrophilic to hydrophobic surface conditions can play a role. We hypothesize that each crossroad (e.g. between organic carbon/clay ratio and matric potential) may control how soil self-organization will manifest itself at a given time as affected by gradients in energy and moisture from soil use and climate. The road map may serve as inspiration for renewed and multi-disciplinary focus on functional soil architecture.

Published by Copernicus Publications on behalf of the European Geosciences Union. 


\section{Soil-it-is}

The upper few meters of the soil sustain our life and society, but we have an incomplete knowledge on how soil behaves. As a contribution towards a better understanding of soil functional behaviour, we recently started an international framework program on functional soil architecture, called "Soil-itis" (Soil Infrastructure, Interfaces \& Translocation Processes in Inner Space).

With the Soil-it-is programme we wish to explore how soil architecture and infrastructure (pore and particle networks) control and are controlled by relatively poorly understood soil-physical and hydrological phenomena in all three soil phases (water, air, solids). The phenomena include soil-water repellency and fingered water flow, diffusive and convective gas transport in variably-saturated pore networks, colloid mobilization/release, and transport of colloids and colloidbound chemicals.

The Soil-it-is vision is a holistic understanding of architecture and processes in soil inner space that will contribute to the basis for solutions to protect groundwater resources, improve clean-up technologies at polluted sites, enhance the health and productivity of cultivated soil, and improve the understanding of the Earth's Critical Zone (CZ), which is defined as the "heterogeneous, near surface environment in which complex interactions involving rock, soil, water, air, and living organisms regulate the natural habitat and determine the availability of life-sustaining resources" (NRC, 2001).

The soil vadose zone, being part of the $\mathrm{CZ}$, is a dissipative system, which is characterized by self-organization far from thermodynamic equilibrium (Young and Crawford, 2004; Vogel and Babel, 2006). It has an immense activity of life, with microbes and fungi playing a key role in the organization and stability of soil organomineral complexes. The soil system may be studied by reductionistic approaches at the level of microbes and isolated mineral particles. We aim at understanding and quantifying functional architecture and pore network dynamics as emergent properties at the aggregate to pedon scale. This is relevant for, e.g., optimizing soil management in cultivated land productivity and soil recovery, prediction and control of soil greenhouse gas emissions and uptake, realistic risk assessment (regarding chemical fluxes from soil to indoor air and to groundwater), and design of in-situ remediation strategies at urban polluted soil sites.

A platform hypothesis in the Soil-it-is programme is that there is a lower limit (threshold) for soil organic matter $(\mathrm{OM})$, below which the self-organization of soil changes character, compromising the functions and services described above. A low level of structurally active OM seems to dramatically increase the risk of clay dispersion. This in turn may increase soil internal vertical erosion. Mobilized clay colloids may be transported in macropores or inter-aggregate pores to the aquatic environments, strained at lower soil hori- zons, or crusted on the walls of soil inner space pores. To quantitatively evaluate this, gas transport studies provide an indirect but strong tool to describe the "morphology" of soil pores across scales, while mechanical disturbance of intact soil and fragments of soil in water in combination with analyses of structural strength across scales can be used to characterize the soil matrix.

A number of functional soil structure indices have been proposed that may both link soil structure to translocation and interface processes and help define the thresholds where soil structure is either improved, maintained (structure resilience) or destroyed in given processes. Examples include the Skopp et al. (1990) "Optimal Water Content" concept where solute and gas diffusivities are at a combined optimum for soil aeration and aerobic microbial activity, the Håkansson (1990) "Degree of Compactness" concept as linked to soil and crop productivity, the Moldrup et al. (2000) "Water-induced Linear Reduction" concept for separating resistances from solids and water on gas-filled pore network tortuosity and connectivity, the Or et al. (2007) "Soil Physical Constraints" concept emphasizing soil-water matric potential, water distribution and water film geometries and thickness as key controls of biological activity, biodiversity and bioactivity, the Dexter et al. (2008) "Clay Saturation" concept separating clay-complexed or non-clay-complexed soil organic carbon (OC) in relation to soil functions and health, and the Robinson et al. (2009) "Natural Capital of Soils" concept where soil moisture, temperature and structure emerge as valuable stocks alongside the more traditionally viewed stocks such as inorganic and organic materials.

Interestingly, as will be shown in this study, the various indices and concepts for functional soil structure (here called soil infrastructure) may be consistent with each other, both in terms of how key translocation parameters (e.g. gas transport parameters) can be used to characterize soil infrastructure and how parameter thresholds for soil structure (e.g. "clay saturation" by OC) control translocation and interface processes. To link the hitherto empirical soil infrastructure indices to a more conceptual understanding and quantification of soil architecture requires that many different physical, chemical, microbiological, and hydropedological parameters for both solid, water, and air phases and interfaces are measured on the same intact or minimally disturbed soil systems across moisture and management conditions. Examples will be given in the next two sections on soil infrastructure and interface processes, but initially we want to clarify the five most central notions used in the manuscript:

1. Soil architecture: The pore and particle networks and their interfaces/surfaces form fascinating and seemingly chaotic soil architecture, created by nature from basic building blocks (biotic and abiotic solids, water and solutes) and influenced by man during soil use and management. 
2. Soil infrastructure (functional soil architecture): The parts of the pore and particle networks and their adjoining interfaces/surfaces that are active in translocation processes.

3. Translocation process: Movement of a soil constituent (water, solute, gas, colloid) between networks and interfaces/surfaces.

4. Self-organization: Young and Crawford (2004) suggested that the soil-microbe system should be regarded as self-organized. Self-organization is a process where the organization of a system spontaneously increases with time, i.e. without this increase being controlled by the environment or an encompassing or otherwise external system (Heylighen, 2001). When a self-organized system is disturbed, its resistance to change from the equilibrium state as well as its resilience to return to this equilibrium state is challenged (Holling, 1973). We will not address the more specific and subtle aspects of the processes in self-organization but rather examine empirically, whether our hypothesis of a lower threshold in organic matter content for sustaining self-organization in a form securing important soil functions can be confirmed.

5. Clay saturation: Dexter et al. (2008) recently showed that arable soils often display a ratio, $\mathrm{n}$, between $<2 \mu \mathrm{m}$ mineral particles (clay) and OC close to or higher than $10(n=$ clay/OC $=10)$. Their results further indicated that for such soils, some selected soil physical properties correlated to the content of OC.

Dexter et al. (2008) defined "complexed clay", CC, as given in Eq. (1)

$\mathrm{CC}=(n \mathrm{OC})$ if $(n \mathrm{OC}<$ clay $)$ else $\mathrm{CC}=$ clay

where $n=10$, and the amount of non-complexed clay, NCC, as given in Eq. (2)

$\mathrm{NCC}=($ clay-CC $)$ if $($ clay-CC $)>0$ else $\mathrm{NCC}=0$

The amount of complexed organic carbon, COC can be calculated by Eq. (3)

$$
\mathrm{COC}=\mathrm{OC} \text { if }(\mathrm{OC}<\text { clay } / n) \text { else } \mathrm{COC}=\text { clay } / n
$$

and the amount of non-complexed OC (NCOC) can be calculated by Eq. (4)

$\mathrm{NCOC}=(\mathrm{OC}-\mathrm{COC})$ if $(\mathrm{OC}-\mathrm{COC})>0$ else $\mathrm{NCOC}=0(4)$

In this study, we specifically revisit some recently published data on different Danish soils supplemented by a few European soils. We re-analyze data to take a closer look at direct and in-direct changes in functional soil architecture as derived from measurements of gas, water and solid-phase properties including diffusive and convective gas transport parameters, water dispersible colloids, soil water repellency, and sorption of dissolved and vapor-phase gases at different moisture (soil-water matric potential) conditions.

The study is divided into three parts. Firstly, we take a renewed look at soil infrastructure with its complementary particle and pore network dynamics. A range of studies on surface soils with clay/OC ratios on either side of the Dexter et al. (2008) threshold is analyzed empirically with respect to soil structural stability as well as the characteristics of the soil pore system. By this we attempt to identify a quantitative shift in soil behavior and appearance and to relate this to the Dexter et al. (2008) threshold. Secondly, we consider a number of interface processes (water repellency and sorption of dissolved and vapor-phase chemicals) to see if the possible controls for soil self-organization and certain interface phenomena could be similar or related. Finally, we suggest a new concept for looking at functional soil architecture, making the first draft of a scientific road map to soil inner space where the crossroads between key biophysical parameters encounter gradients in applied mechanical energy and soil water intensity and hereby decide the dynamics of breakdown, resilience, or build-up of soil infrastructure.

\section{Infrastructure: the soil particle and pore networks}

\subsection{The soil matrix}

For surface soils, the basic process in formation of soil structure is physicochemical interaction between mineral and organic substances. Dispersible clay and $\mathrm{Fe}$ - and Al-oxyhydroxides flocculate, influenced by organic bonding agents, e.g., extracellular polymeric substances excreted from plants, fauna, and microbes. At larger scales fungal hyphae and plant roots cross-link and enmesh the matrix. This traditional hierarchical soil aggregation concept is described in Tisdall and Oades (1982) and references therein. Clay mineralogy governs the mechanisms active in aggregation, and most soils need OM to create stable macro-aggregates (Denef and Six, 2005). Recent achievements focus on the role of $\mathrm{OM}$ in re-arranging mineral particles into an open structure (Or et al., 2007). Clay minerals are the basic level in the hierarchy of soil structural elements. If the organization of clay particles - i.e. the interaction between clay and OM - is lost, all other hierarchical orders are lost or absent (Dexter, 1988). Re-orientation and hardening of dispersed clay minerals may result in a dense and mechanically strong but non-friable soil (Watts and Dexter, 1997, 1998). Evidence exists that $\mathrm{OM}$ in soil will reduce or prevent cementation (e.g. Utomo and Dexter, 1981; Kemper et al., 1987; Dexter, 1988). A similar situation exists in 'hard-setting' soils of subtropical and tropical areas, where oxyhydroxides need 


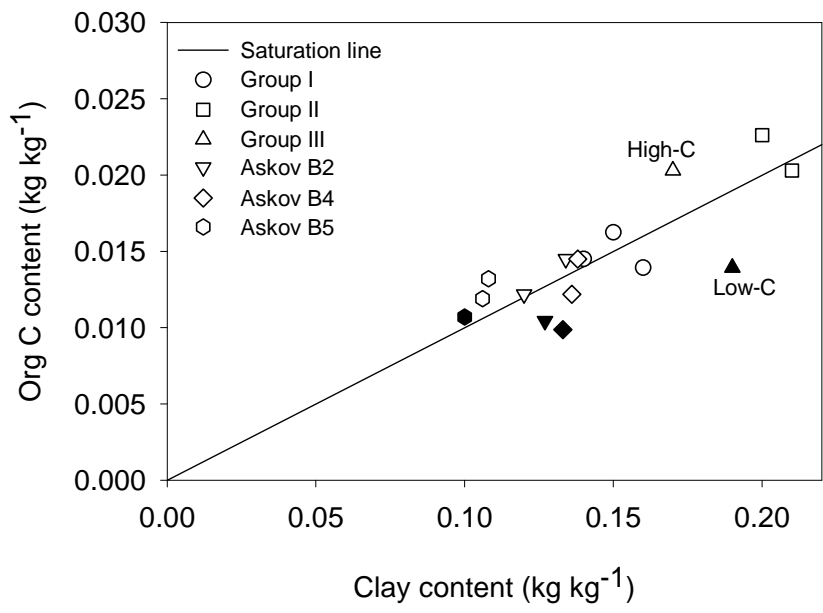

Fig. 1. Relation between the content of clay and OC for a range of Danish surface soils with different soil management. Results on soil physical characteristics were reported for the Group I through Group III soils by Munkholm et al. (2001) and Schjønning et al. (2002a), the Askov B2 and B4 fields were studied by Munkholm et al. (2002), and the Askov B5 soil by Schjønning et al. (1994). Soils with poor tilth conditions are shown by closed symbols. The soils labelled with "Low-C" and "High-C" are those discussed in detail in Figs. 2 through 6.

OM to facilitate satisfactory tilth conditions (Mullins et al., 1987).

\subsubsection{Applying the Dexter et al. (2008) threshold for complexed clay}

For mechanically undisturbed soils like pasture, Dexter et al. (2008) typically found clay/OC ratios lower than 10. Such soils are often described as having passed their "capacity factor" for carbon sequestration (Ingram and Fernandes, 2001; Carter et al., 2003), and Dexter et al. (2008) found that the physical properties for these soils were not determined by OC but rather by the clay content. This observation is ground-breaking because it brings a functional approach into the debate on SOM mostly dominated by a focus on the sequestration of carbon (e.g. Hassink, 1997; Mayer and Xing, 2001).

Dexter et al. (2008) showed that non-complexed clay is more easily dispersed in water than is clay complexed with OC. We have previously studied a range of arable soils (Schjønning et al., 2002a). For six of these soils having satisfactory tilth conditions the clay/OC ratio averaged $9.7 \pm 1.2$ (standard deviation). A similar calculation on data from the long-term fertilization experiment at Askov, Denmark, shows that soil receiving either animal or mineral fertilizer at adequate rates for a century in three replicate experimental fields had a clay/OC ratio of $9.5 \pm 1.0$ (Schjønning et al., 1994). According to the suggestion of Dexter et al. (2008), the clay of all these soils is virtually saturated with OC
(clay/OC 10). In contrast, soil unfertilized for a century at the Askov experiment had an average clay/OC ratio of $11.7 \pm 2.0$. This is an indication of a pool of non-complexed clay (NCC, Eq. 2), and the soil treated in this way in all three replicate fields displayed severe signs of structural degradation (e.g., weak in wet conditions, mechanically strong in dry conditions). One of the soils studied in Schjønning et al. (2002a) was also depleted in OC due to long-term continuous growing of small-grain cereals without any return of organic residues and manure to the soil. For that soil, the clay/OC ratio was as high as 13.7, and significant signs of degradation of soil structure was found (Munkholm et al., 2001; Schjønning et al., 2002a). A detailed study of water dispersibility of clay (WDC) by Elmholt et al. (2008) indicates, for soil samples collected across this Low-C soil and only this soil - a correlation between WDC and OC expressed as the hot-water extractable $\mathrm{C}$ fraction.

The above supports the theory suggested by Dexter et al. (2008) of a lower threshold of OC for sustaining the selforganization process in soil. Dexter et al. actually revealed a clay/OC ratio for "saturation" of complexed OC on the clay particles in the range $8-11$ (hence suggesting 10 as a suitable limit). This is in rather close agreement with the clay/OC ratios for the Danish arable soils reviewed above that have no tilth problems, while those displaying poor tilth conditions had higher values. More studies are needed, nevertheless, to investigate the general validity of one specific clay/OC ratio across soil types. The relation between clay and OC for the soils discussed here is shown in Fig. 1. We note that the Dexter et al. (2008) concept applied to our data provides evidence that soil tilth conditions are determined by the degree of OC complexation of clay minerals rather than by OC.

\subsubsection{Water-dispersible clay and aggregate stability}

Several studies have shown that the water-dispersible clay (WDC) content is smaller when the soil OC content is larger (e.g. Watts and Dexter, 1997; Czyz et al., 2002). Dexter et al. (2008) found a higher correlation between WDC and soil clay content if NCC rather than total clay is used, which is in support of their hypothesis of two functionally different OC fractions. Based on our previous studies of the $\mathrm{C}$-exhausted soil mentioned above (Fig. 1: Low-C soil of Group III), we hypothesize that the self-organization of soils with $\mathrm{NCC}>0$ may change character towards undesirable soil conditions. Table 1 shows results from the Low-C soil and a neighbouring matching soil managed with forage crops and return of OM to the soil (High-C) (Munkholm et al., 2001; Schjønning et al., 2002a; Elmholt et al., 2008). We note (Table 1) that the soil content of total as well as a labile OC fraction is significantly higher for the High-C soil than the Low-C soil. A calculation based on Dexter et al. (2008) found no NCC for the High-C soil, while the clay of the Low-C soil was not saturated $(\mathrm{NCC}>0)$. In accordance with the general expectation, WDC of field-moist soil in a low-energy test was found 
Table 1. Selected soil characteristics for the 6-13 cm layer of two arable soils with management-derived differences in OM (modified after Munkholm et al., 2001; Schjønning et al., 2002a; Elmholt et al., 2008). Within each row, figures followed by different letters (a,b) are significantly different (one-way analyses of variance taking the intra-field residual variance as error term; $P=0.05$ ). Sample size $n=9$.

\begin{tabular}{|c|c|c|}
\hline \multirow{2}{*}{ Soil characteristics } & \multicolumn{2}{|c|}{ Management system } \\
\hline & High-C-input & Low-C-input \\
\hline Soil org. $\mathrm{C}$, total ( $\mathrm{mg} \mathrm{g}^{-1}$ soil) & $19.7 b$ & $14.3 \mathrm{a}$ \\
\hline Soil org. $\mathrm{C}$, hot-water extractable ( $\mu \mathrm{g} \mathrm{g}^{-1}$ soil) & $232 b$ & $202 \mathrm{a}$ \\
\hline Non-complexed clay $(\mathrm{NCC})\left(\mathrm{mg} \mathrm{g}^{-1} \text { soil }\right)^{\mathrm{a}}$ & 0 & 51 \\
\hline Water-dispersible-colloids of wet soil ( $\mathrm{mg} \mathrm{g}^{-1}$ clay) & $98 \mathrm{a}$ & $134 b$ \\
\hline Water-dispersible-colloids of dry aggregates ${ }^{\mathrm{b}}$ ( $\mathrm{mg} \mathrm{g}^{-1}$ clay) & $20.6 b$ & $18.0 \mathrm{a}$ \\
\hline Tensile strength of dry aggregates ${ }^{\mathrm{c}}(\mathrm{kPa})$ & $215 \mathrm{a}$ & $267 b$ \\
\hline Wet macro-aggregate stability ${ }^{\mathrm{d}}\left(\mathrm{mg} \mathrm{g}^{-1}\right.$ soil) & $637 \mathrm{a}$ & $873 b$ \\
\hline
\end{tabular}

a Calculated according to Dexter et al. (2008)

$\mathrm{b}$ Averaged across three aggregate sizes, $0.063-0.25,0.5-1,4-8 \mathrm{~mm}$

c Averaged across four aggregate sizes, $1-2,2-4,4-8$ and $8-16 \mathrm{~mm}$

$\mathrm{d}>0.25 \mathrm{~mm}$ aggregates after Yoder-type wet-sieving for two minutes
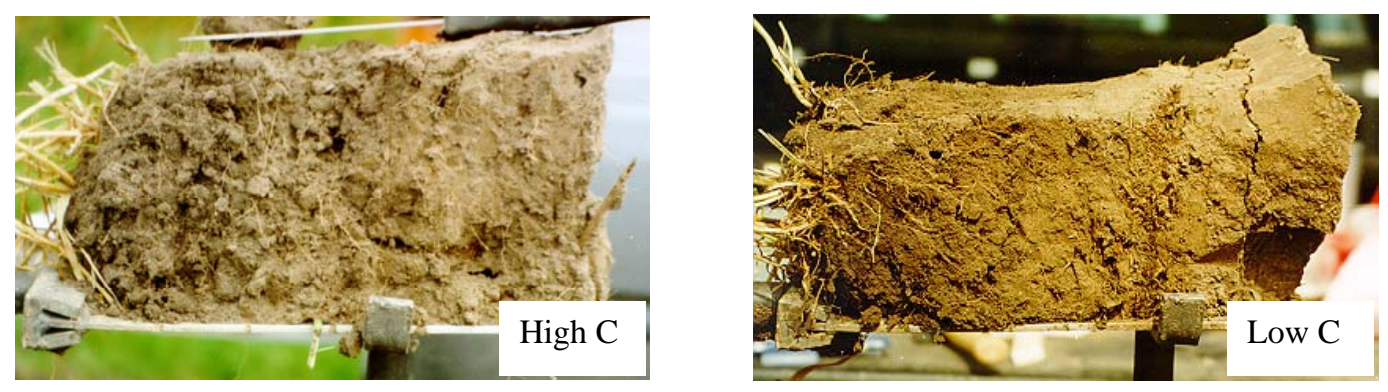

Fig. 2. Photos of the top $30 \mathrm{~cm}$ of the High-C soil (left) and the Low-C soil (right) used for evaluation of organic depletion effects on the soil matrix and soil pores (reproduced from Schjønning et al., 2002a).

to be significantly highest for the Low-C soil. However, it is noticeable that a significantly lower amount of WDC was found for the Low-C soil when testing air-dried soil with the same energy input as for the wet soil (Table 1).

We interpret the results as an indication of cementation of readily dispersible clay in the drying process - and hence a decrease in dispersibility in a new short-term process of water application and energy input. This is supported by the high level of tensile strength of air-dried aggregates found for that soil; the cemented clay has formed internal crusts in the aggregates of the Low-C soil, hence producing mechanically stronger clods compared to the High-C soil. It is noteworthy that this is reflected also in a classical Yoder-type wetsieving test; the Low-C soil displayed significantly higher aggregate stability than the High-C soil (Table 1). Thus, high stabilities of aggregates in wet conditions can be due to either cemented clay in low-friable clods or to biotic bonding and binding mechanisms in healthy crumbs (Schjonning et al., 2007; Elmholt et al., 2008). Other studies have likewise reported a poor correlation between dispersibility of clay and wet aggregate stability (Williams et al., 1966; Molope et al.,
1985; Pojasok and Kay, 1990). The effect of organic depletion on the soil matrix and soil pores is visually illustrated in Fig. 2. As mentioned above these two soils come from the same soil type and parent material i.e., from two fields located only $\sim 200 \mathrm{~m}$ apart, but treated very different agriculturally. The colour difference of the soils is an artefact of the photos, but what should be noted is the individual aggregates and macropores of the High-C soil as compared to the dense blocky structure of the Low-C soil.

Low levels of soil $\mathrm{OM}(\mathrm{NCC}>0)$ may create aggregates that are unstable in wet conditions but become hard and strong in dry conditions (Watts and Dexter, 1997; Munkholm et al., 2001, 2002; Schjønning et al., 2002a). This has major impacts on agronomic aspects like tillage but also on clay dispersibility/colloid mobilization and hence colloidfacilitated transport of environmental pollutants (de Jonge et al., 2004ab).

Colloid mobilization, stability, and transport in soil inner space are newly recognized and not-yet understood processes. The physical deposition of colloids on pore network walls (straining) may cause clogging of networks and 


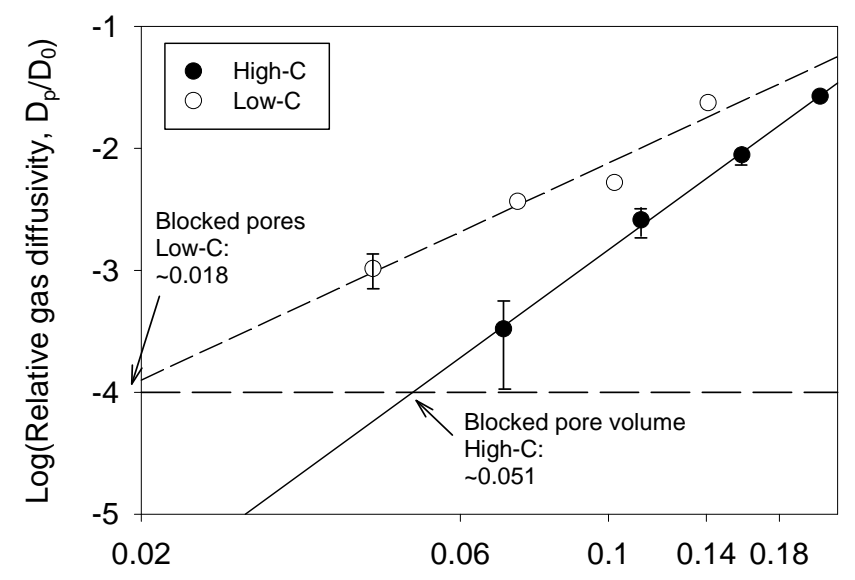

Air-filled pore space, $\varepsilon_{\mathrm{a}}\left(\mathrm{m}^{3} \mathrm{~m}^{-3}\right)$

Fig. 3. Gas diffusivity for top layer soil of two arable soils with contrasting contents of management-derived OM (calculated from Schjønning et al., 2002b). Consult text for details. Error bar indicate standard error. Sample size $n=9$.

dramatically changed soil architecture and infra-structure, affecting transport of colloid-bound chemicals through the soil vadose zone (de Jonge et al., 2004a; Sen and Khilar, 2006). These processes completely redefine our ideas about soil inner space dynamics. However, colloid transport has only recently been considered in models for transport and fate processes in the Critical Zone (Bradford and Torkzaban, 2008) due to a lack of process knowledge. Soil physical disturbance, soil solution chemistry, and ambient soil moisture status all control colloid mobility (Kjaergaard et al., 2004) and thereby colloid-bound chemical transport (de Jonge et al., 2004a). Recent results further imply that the transport of colloids is controlled by mechanisms very different from those for dissolved chemicals and that soil structure (architecture) and preferential water flow are essential phenomena for quantifying colloidal transport in natural, undisturbed soils (Poulsen et al., 2006). Thus, there is considerable scope in studying colloid mobility and transport in the context of soil architecture and the self-organization concept.

\subsection{The soil pore system}

The soil pore networks represent the complementary or "mirror image" of the soil particle networks (soil matrix). Hereby, the pore networks will be affected by any changes in the soil matrix. Simultaneously, any changes in soil moisture conditions will affect the functional pore networks for both gas and water transport since additional water will form water bridges for water and solute transport but water blockages for air and gas transport. An even minor additional water input to the pore network system can create dramatic changes in numerous transport properties since the additional water bridges/blockages will typically be located at the nar- row pore throats where the particles are most closely adherent (Moldrup et al., 2001). At near-water-saturation the air and gas transport pathways are typically minimized or eliminated while especially the well-connected parts of the largepore network will facilitate preferential transport of water, solutes, and colloids. Opposite, at dryer conditions the gas transport pathways are being increasingly activated depending on the improvements in pore connectivity. Thus, the soil infra-structure defined by the complimentary pore and particle networks together with moisture conditions will affect all translocation processes.

While state-of-the-art visualization methods can identify different, mainly large-pore size classes at limited moisture conditions, our ability to identify pore network connectivity across moisture conditions and thereby find quantitative links to translocation processes is still today very limited. Direct and non-destructive measurements at controlled moisture conditions of transport parameters related to the functional (active) part of the soil pore network are therefore valuable for characterizing the soil pore system. As opposed to water and dissolved tracer experiments, gas transport experiments will typically not affect the soil sample that is being measured on, suggesting gas transport measurements across controlled soil moisture conditions can offer a more true fingerprint of soil infrastructure (Moldrup et al., 2003a, b).

\subsubsection{Characterizing the soil pore system}

Combined measurements of soil-gas diffusivity and air permeability are powerful means of characterising pore system dynamics in undisturbed soil (e.g., Ball, 1981; Moldrup et al., 2001). The breakdown of clay-OM interaction may induce distinct changes in the soil pore network. In a previous study (Schjønning et al., 2002b), a combination of gas diffusion and air permeability measurements were used to describe the pore system of intact soil cores collected in the same fields with contrasting management as addressed in the section on the soil matrix (Table 1). Figure 3 shows measured gas diffusivity for the two soils at four water potentials. The estimates of pore volumes blocked from the surrounding atmosphere (see data in the figure) were found by assuming i) a simple power law relationship between gas diffusivity and the air-filled pore space, and ii) a lower threshold of $D_{p} / D_{0}=10^{-4}$, (where $D_{p}$ and $D_{0}$ are the gas diffusion coefficients in soil and air, respectively) reflecting no gas phase diffusion (Weast et al., 1983). I.e., we interpret the estimates of air-filled pore volume at this diffusivity threshold to reflect air encapsulated in the bulk soil (blocked pore space). From the figure, we note that the High-C soil returns the highest estimate of blocked pore space, which may be interpreted as a first indication of a different soil architecture for that soil.

Moldrup et al. (2000) showed that for sieved, repacked soil in a wide texture range (between 6 and 54\% clay) the soil relative gas diffusivity was, with high accuracy, predicted by the model (Eq. 5): 


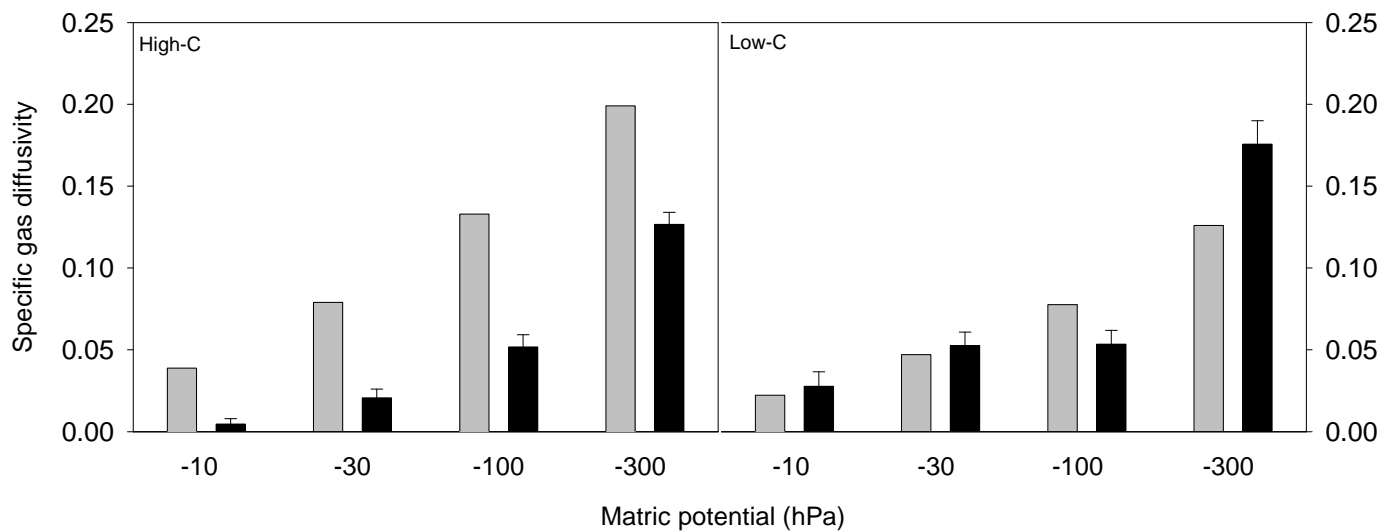

Fig. 4. Specific gas diffusivity $\left(D_{p} /\left(D_{0} \varepsilon_{a}\right)\right)$ calculated from measured diffusivities and air-filled porosities (black bars) and from the WLR (Marshall) model with the measured air-filled porosities. Please consult text for details. Based on data from Schjønning et al. (2002b). Error bar indicate standard error. Sample size $n=9$.

$\frac{D_{p}}{D_{0}}=\frac{\varepsilon_{a}^{2.5}}{\Phi}$

where $\varepsilon_{a}$ is the volume of air-filled pore space, and $\Phi$ is soil total porosity. This so-called water-induced linear reduction model, WLR (Marshall), indicates that for structure-less soil, the reduction in relative diffusivity may be explained solely by increasing water content (decreasing $\varepsilon_{a}$ ) at a given compaction level (and thus $\Phi$ level). We now hypothesize that the soil structure of the Low-C soil with dispersion-cementation cycles of clay - as discussed in the previous section - has degraded to mimic a sieved soil, i.e. obeying the WLR (Marshall) model for gas diffusion. For this, we use the specific gas diffusivity as the ratio between the relative gas diffusivity and the volume of air-filled pore space:

$\frac{D_{p}}{\left(D_{0} \varepsilon_{a}\right)}=\frac{\frac{\varepsilon_{a}^{2.5}}{\Phi}}{\varepsilon_{a}}=\frac{\varepsilon_{a}^{1.5}}{\Phi}$

Figure 4 (right) shows that for four matric potentials investigated, the specific gas diffusivity $\left(D_{p} /\left(D_{0} \varepsilon_{a}\right)\right)$ derived from measured data (black bars) is indeed approximately similar to those estimated from the WLR(Marshall) model for the measured $\varepsilon_{a}$ values (grey bars). In contrast, the High-C soil exhibits a specific gas diffusivity much lower than predicted from the WLR (Marshall) model. This reflects a much more tortuous/complex pore system than found for the Low-C soil. The same clear trend may be depicted from the independent measurements of convective gas flow in the pore systems. Groenevelt et al. (1984) suggested the specific air permeability as an index analogous to the specific gas diffusivity for expressing the continuity of soil pores. The specific air permeability is nearly an order of magnitude higher for the Low-C than for the High-C soil (Fig. 5). This means that the pore system of the Low-C soil is dominated by continuous (macro)pores enabling a fast convective transport of air through the soil.

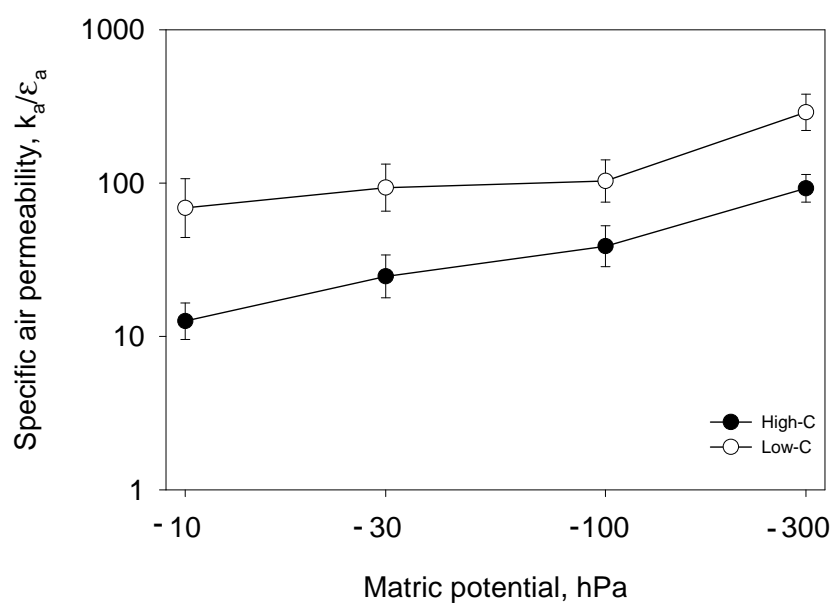

Fig. 5. Specific air permeability $\left(k_{a} / \varepsilon_{a}\right)$ at four soil-water matric potentials. Based on data from Schjønning et al. (2002b). Error bar indicate standard error. Sample size $n=9$.

Following Moldrup et al. (2001), but including the effect of inactive air-filled porosity (Brooks and Corey, 1966) as found in Fig. 3, we further evaluate the air-filled porenetwork characteristics from a simple power-law model for relative gas diffusivity,

$$
\frac{D_{p}}{D_{0}}=\left(\frac{\left(\varepsilon_{a}-\varepsilon_{a p}\right)}{\left(\varepsilon_{a}^{*}-\varepsilon_{a p}\right)}\right)^{M}
$$

where $\varepsilon_{a p}$ is the inactive air-filled porosity or percolation threshold (Hunt, 2005), $\left(\varepsilon_{a}-\varepsilon_{a p}\right)$ is the active air-filled porosity, $M$ is a tortuosity-connectivity coefficient (Moldrup et al., 2001), and $\varepsilon_{a}{ }^{*}$ is a chosen reference air-filled porosity. We note that the often applied assumption of $\varepsilon_{a p}=0.1 \times \Phi$ (Hunt, 2005) approximately applies to the HighC soil $\left(\varepsilon_{a p}=0.051 \mathrm{~m}^{3} \mathrm{~m}^{-3}, \Phi=0.473 \mathrm{~m}^{3} \mathrm{~m}^{-3}\right)$, but largely 


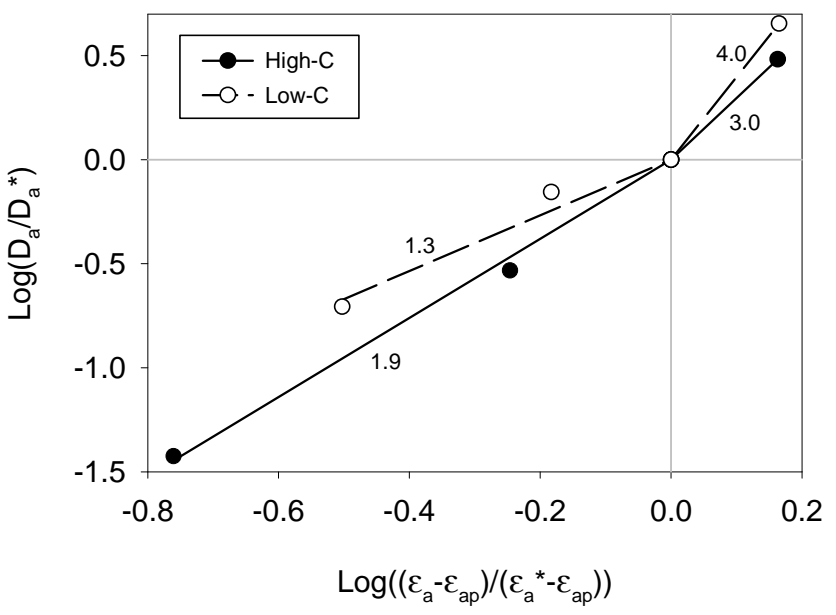

Fig. 6. Normalized relative gas diffusivity, $D_{p} / D_{0}^{*}$, plotted towards normalized air-filled porosity active in the diffusion process, $\left(\varepsilon_{a}-\varepsilon_{a p}\right) /\left(\varepsilon_{a} *-\varepsilon_{a p}\right)$, in a log-log presentation as suggested by Moldrup et al. (2001) and with a soil-water matric potential of $-100 \mathrm{hPa}$ as the reference point. The figures next to the regression lines give the slopes for the respective parts of the water potential range. Calculated from data of Schjønning et al. (2002b).

over-estimates $\varepsilon_{a p}$ for the Low-C soil $\left(\varepsilon_{a p}=0.018 \mathrm{~m}^{3} \mathrm{~m}^{-3}\right.$, $\Phi=0.420 \mathrm{~m}^{3} \mathrm{~m}^{-3}$ ), suggesting much higher connectivity and continuity of inter-ped pores in the Low-C soil. We chose $\varepsilon_{a p} *$ at $-100 \mathrm{hPa}$ and note pores drained between $-10 \mathrm{hPa}$ and $-100 \mathrm{hPa}$ inter-ped or macro-pores (Moldrup et al., 2004 ) and pores additionally drained between $-100 \mathrm{hPa}$ and $-300 \mathrm{hPa}$ intra-ped or smaller pores. Figure 6 shows the plot of $\log \left(D_{p} / D_{0}\right)$ versus $\log \left[\left(\varepsilon_{a p}-\varepsilon_{a p}\right) /\left(\varepsilon_{a}{ }^{*} \varepsilon_{a p}\right)\right]$ with the airfilled porosity at the reference point soil-water matric potential represented by the value of 0 on the $\mathrm{x}$-axis (vertical dotted line). The slope to the left of $\log \left[\left(\varepsilon_{a}-\varepsilon_{a p}\right) /\left(\varepsilon_{a}{ }^{*}-\varepsilon_{a p}\right)\right]=0$ represents the inter-ped tortuosity-connectivity factor $\left(M_{1}\right)$ and the slope to the right of $\log \left[\left(\varepsilon_{a}-\varepsilon_{a p}\right) /\left(\varepsilon_{a}{ }^{*} \varepsilon_{a p}\right)\right]=0$ the intraped tortuosity-connectivity factor $\left(M_{2}\right)$. The ratio of $M_{2}$ to $M_{1}$,

$m=\frac{M_{2}}{M_{1}}$

represents the change in pore network characteristics (connectivity, continuity and tortuosity) between intra- and interped regions. The large $m$ value of $\sim 3$ for the Low-C soil (as compared to $\sim 1.5$ for the High-C soil) implies a dramatic change in soil architecture between intra- and inter-ped regions, again supporting the hypothesis of a more pipe-like pore-network architecture for the Low-C soil. We therefore suggest $m$ to be a useful soil architecture index. Please consult Moldrup et al. (2001) and Hunt (2005) for a more detailed explanation of the basis for this analysis.

Recalling the distinctly larger amount of non-complexed clay and hence the higher WDC for the Low-C compared to the High-C soil (Table 1), we note that the higher $M_{2}$ value
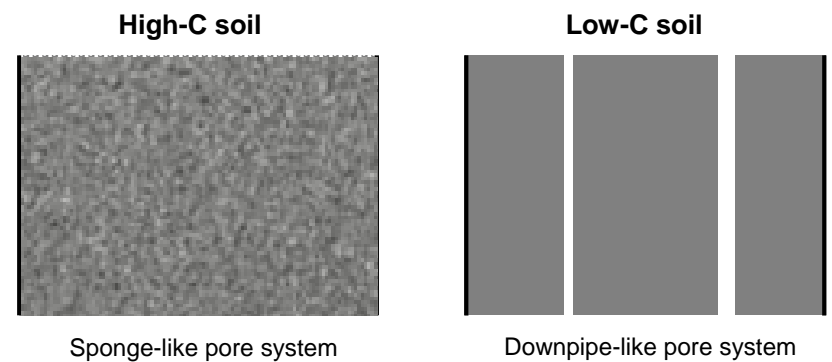

Fig. 7. Conceptual representation of the sponge-like pore system for a high-C soil with active self-organization and a low-C soil, where internal crusting of dispersed clay has created a pipe-like pore system with poor contact between micro- and macropores.

of the Low-C soil (Fig. 6) may reflect internal crusting within peds for that soil. This interpretation needs to be confirmed by other studies, but has crucial impacts on several soil functions related to soil productivity as well as environmental aspects.

\subsection{Soil behavior at critical organic matter contents}

Combining the pore system fingerprints obtained by the analyses performed above, we suggest that the pore system of a C-depleted soil may turn into a downpipe-like appearance in contrast to a well-managed soil exhibiting self-organization where our data indicate a "sponge-like" appearance (Fig. 7). We see a causal relation between the observed pore networks and the behaviour of the soil matrix when mechanically disturbed in wet and dry conditions (Table 2). Dexter et al. (2008) found a linear relation between NCC and key physical soil properties. Our data indicate that non-linear behaviour (e.g. strongly cemented clods rather than friable aggregates) due to a qualitative shift in soil self-organization may be expected at considerable levels of NCC. It may be claimed that crusting and straining of clay particles is still an increase in organization. Thus Swift (1994) emphasized that resilient systems may have the capacity to occupy more than one state of equilibrium. There is, however, no doubt that a range of important soil functions in crop production and environmental protection will be poorer for the soil with a poor interaction between $\mathrm{OM}$ and clay particles.

\section{Interfaces: processes in the solids-water-air continuum}

\subsection{Water repellency}

Soil functions including water distribution and flow in the soil pore system are governed by interface processes. Water repellency (WR) is such an interface phenomenon, which affects hydrological processes or potentially all processes where water is involved. Critical WR can cause fingered 
Table 2. Soil and system characteristics for soils with clay minerals interacting with OM in a self-organized manner and for soils below a critical threshold of OM.

\begin{tabular}{lcc}
\hline \multirow{2}{*}{ Soil and system characteristics } & \multicolumn{2}{c}{ Structure self-organization } \\
& Active & Collapsed \\
\hline Org. C inputs (crop rotation, manure, etc) & high & low \\
Soil org. C quantity and quality & high & low \\
Non-complexed clay (NCC) & very low or none & $>0$ \\
Water-dispersible-colloids (clay minerals) of wet soil & low & high \\
Mechanical strength of dry soil & low & high \\
Complexity of the soil pore system & high & low \\
\hline
\end{tabular}

a As defined by Dexter et al. (2008)

flow (Fig. 8) and, in turn, preferential leaching of nutrients and chemicals to groundwater. At the smaller scale, the occurrence of interface-induced irregular water flow may also lead to altered soil inner space architecture due to accelerated particle dispersibility in the flow active architecture, which in turn further influences the flow pathways and vice versa. Further it has recently been shown (McHale et al., 2007) that droplet evaporation from water repellent soils can result in a particle sorting effect with self-organization of a mixed hydrophobic-hydrophilic aggregate into a hydrophobic shell surrounding a hydrophilic core, i.e. altered micro architecture.

\subsubsection{Effect of soil moisture and matric potential}

The WR is closely related to soil-water content (de Jonge et al., 1999, 2007), OM quantity/quality (Kawamoto et al., 2007; Regalado et al., 2008), microbial activity (Hallett and Young, 1999), and soil management (de Jonge et al., 2007). Water repellency will at the same time control the onset of unstable (preferential or finger-like (Fig. 8)) water flow events in the soil (Nissen et al., 1999), thereby often causing a poor water distribution and accelerated transport of chemicals to the groundwater. Classical soil physics for describing water and chemical transport assumes that soil is non-waterrepellent. However, recent evidence suggests that at least low levels of water repellency are the rule rather than the exception (Hallett and Young, 1999), and that spatial variations in soil OM quality and microbial activity control this so-called sub-critical water repellency. Consequently, smallscale changes in soil architecture including microbial activity and OM quantity and quality are likely major controls of flow heterogeneity and water distribution - where it was hitherto assumed that macropores and cracks in the topsoil were the main cause of preferential water flow and poor water distribution effects observed worldwide (Hallett et al., 2004; Or et al., 2007).

The WR varies non-linearly with soil-water content, $w$ (King, 1981; Wallis et al., 1990; de Jonge et al., 1999, 2007; Kawamoto et al., 2007; Regalado et al., 2008) and all soils
Table 3. Soil characteristics for Jyndevad, Lundgaard, and Odum soil. These are all surface soils.

\begin{tabular}{lcccc}
\hline & Clay & Silt & $\begin{array}{c}\text { Sand } \\
\mathrm{kg} \mathrm{kg}^{-1}\end{array}$ & Org. C \\
\hline Jyndevad & 0.048 & 0.053 & 0.869 & $0.011-0.028$ \\
Lundgaard & 0.048 & 0.132 & 0.802 & 0.011 \\
Odum & 0.137 & 0.264 & 0.575 & 0.014 \\
\hline
\end{tabular}

finally become wettable above a certain water content. This is illustrated (Fig. 9a) for a coarse-textured Danish soil from Jyndevad (Table 3 ) grown with three different crops of grass, barley and wheat. The trapezoidal integrated area, $S_{W R}(\mathrm{~m}$ $\mathrm{N} \mathrm{m}^{-1} \mathrm{~kg} \mathrm{~kg}^{-1}$ ) under the WR-w curves (de Jonge et al., 2007; Regalado et al., 2008), can be used to determine the overall degree of WR for a specific soil (Fig. 9b). The grass crop clearly produces the highest WR followed by barley and wheat. The ways in which these soils differ are in the quantity and quality of soil organic C. With the same soil texture, what influences the overall level of WR is the type of crop grown on the soil and its interaction with the total amount of OC. The soils grown with small grain cereals have the smallest WR, but also a significantly lower content of OC (Fig. 9b). A comparison of the WR of soil collected from under a grass or barley crop shows a significantly higher WR for the grass crop despite the lower OC content of this soil.

\subsubsection{Effects of the soil matrix and clay saturation}

Fractionating the Jyndevad soil collected from under grass crop allows us to investigate the effect of size fractions on the degree of WR. The Jyndevad soil was fractionated into the fractions: $<0.063 \mathrm{~mm}$; $0.063-0.125 \mathrm{~mm} ; 0.125-0.250 \mathrm{~mm}$; $0.250-0.500 \mathrm{~mm} ; 0.500-1.000 \mathrm{~mm}$; and $1.000-2.000 \mathrm{~mm}$. The degree of WR, $S_{W R}$, for the three smallest size-fractions (as well as the water-content at which the fractions becomes wettable) (Fig. 10a) increases with decreasing size-fractions 

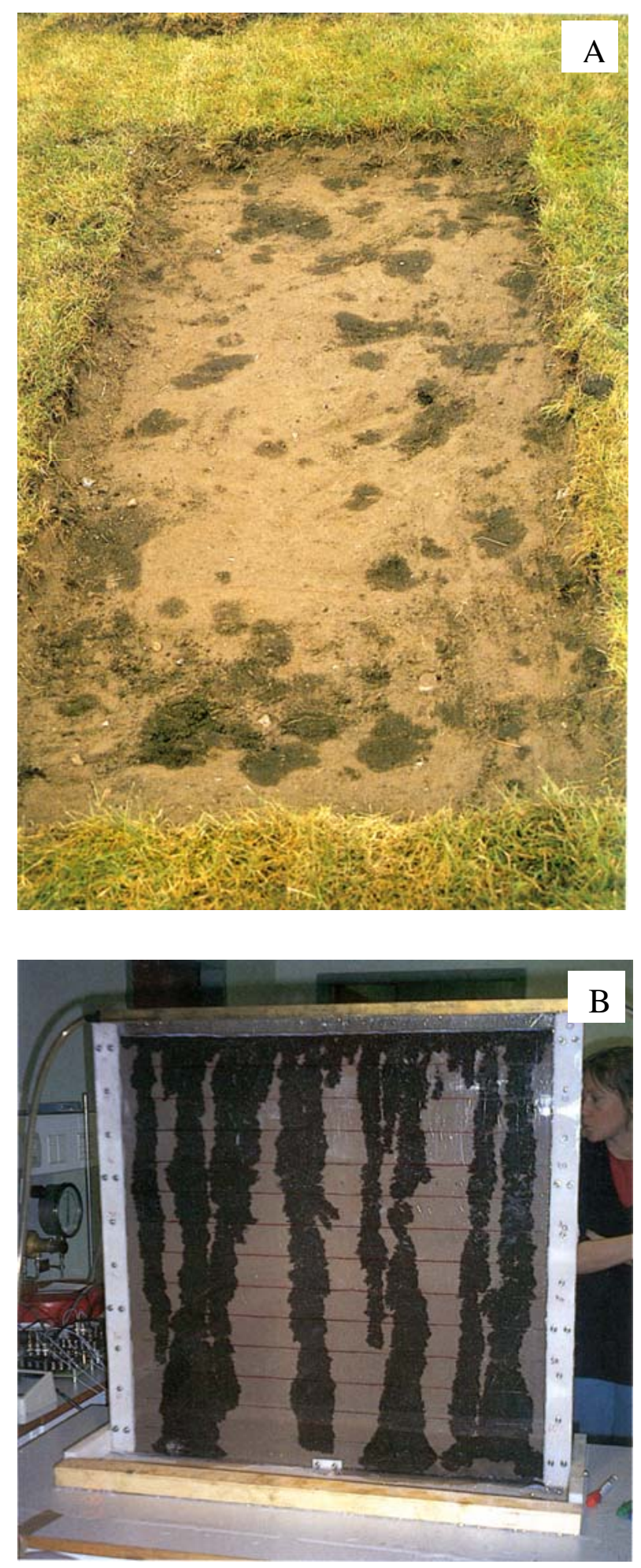

Fig. 8. Fingered flow phenomena in situ and in laboratory experiments. (A) Finger flow in water-repellent sandy soil with permanent grass: $24 \mathrm{~h}$ after intensive irrigation the grass layer was removed. Water infiltrates in fingers leaving large sections dry. (B) Evidence of finger flow in laboratory hele-shaw irrigation experiments on dry water repellent sandy soil. (modified from de Jonge et al., 1999). Taking another and a closer look (Fig. 10b) by plotting the $S_{W R}$ for all fractions as well as the whole soil as a function of soil OC reveals that the degree of WR is actually related to the OC content in the fractions rather than the particle sizes themselves. The OC content obviously plays a dominant role for the water repellency interface phenomenon. In the literature significant effects of OC on a range of soil physical properties have been reported including compactability, tillage, stability in water, and soil physical quality in general (Dexter et al., 2008, and references therein). Usually the effects of OM are such that an increased OM content results in improved soil physical properties. But as for the effects of increased WR with increasing OC content and the possible resulting irregular water movement the positive role is less clear. Subcritical water repellency is a common feature of many soils (Wallis et al., 1991; Hallett and Young, 1999). It is a fundamental physical property of soil and has implications for the resistance of soil structure against disruption by wetting and bypass flow (Hallett et al., 2001).

The OC contents of numerous Jyndevad soil samples (de Jonge et al., 2007) having undergone different treatments are plotted as a function of their clay content (Fig. 11a) along with a number of other soil types, for which the WR-w curve has been determined (de Jonge et al., 1999). Assuming that only the clay content determines $\mathrm{C}$ saturation, all of these soils fall well above the saturation line, which implies that they hold smaller or larger amounts of OC in a noncomplexed form (NCOC, Eq. 4). The degree of WR for these soils, as determined by $S_{W R}$, plotted against the amount of NCOC yields a linear relationship with a Pearson correlation coefficient of $r=0.77^{* * *}$ (note the data points from the Jyndevad grass field, the upper open circles, have been omitted in the correlation analysis due to the influence of eluded OC from the crop). This is only a slight improvement as opposed to correlating against $\mathrm{OC}\left(r=0.76^{* * *}\right.$, analysis not shown), but the regression line hits the origin when correlating with NCOC (interception not significantly different from zero), which is not the case when using OC (analysis not shown). This points towards the WR phenomenon being switched off when no NCOC is present in the soil.

The above analyses imply that OC quantity and quality, soil texture (specific surface area) and soil structure including aggregation may all in combination with actual soil moisture conditions (content and distribution) play a key role in controlling interface processes such as water repellency. They therefore also play a role in controlling surface and subsurface hydrology as well as the spread of contaminants. 

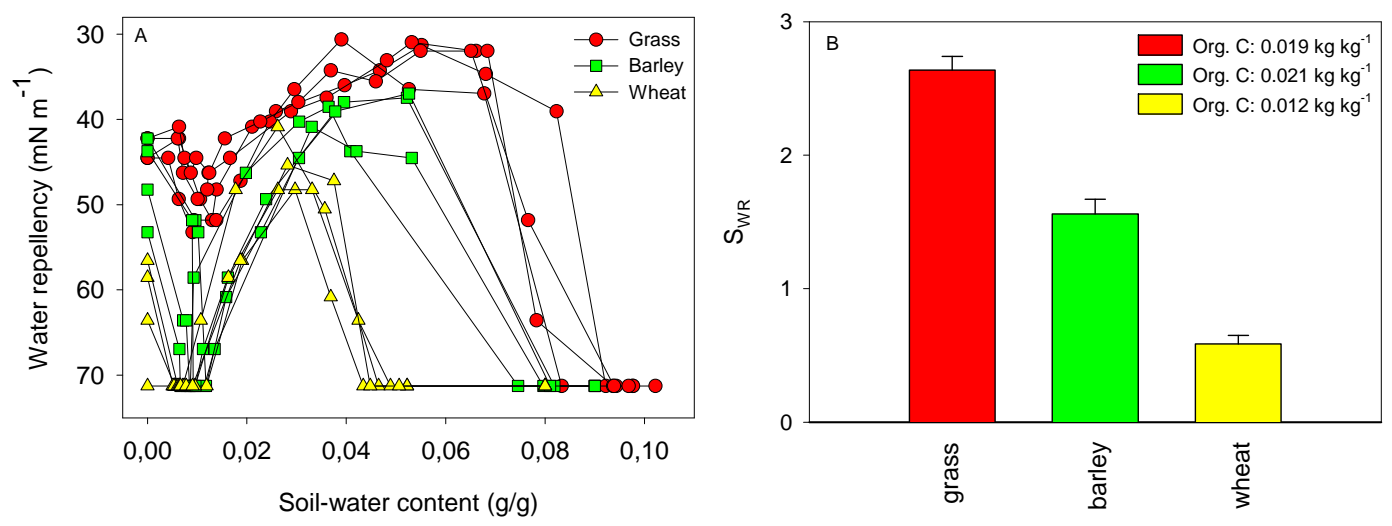

Fig. 9. (A) Soil water repellency versus gravimetric soil-water content curves for three selected crop types grown on the same coarse-textured sandy soil type. Note WR increases with decreasing surface tension $\left(\mathrm{N} \mathrm{m}^{-1}\right)$. Amount and type of soil OM are the two switches influencing the degree of water repellency. Modified from de Jonge et al. (2007). (B) Degree of water repellency given as the areas under WR-w curves as a function of Org. C content.
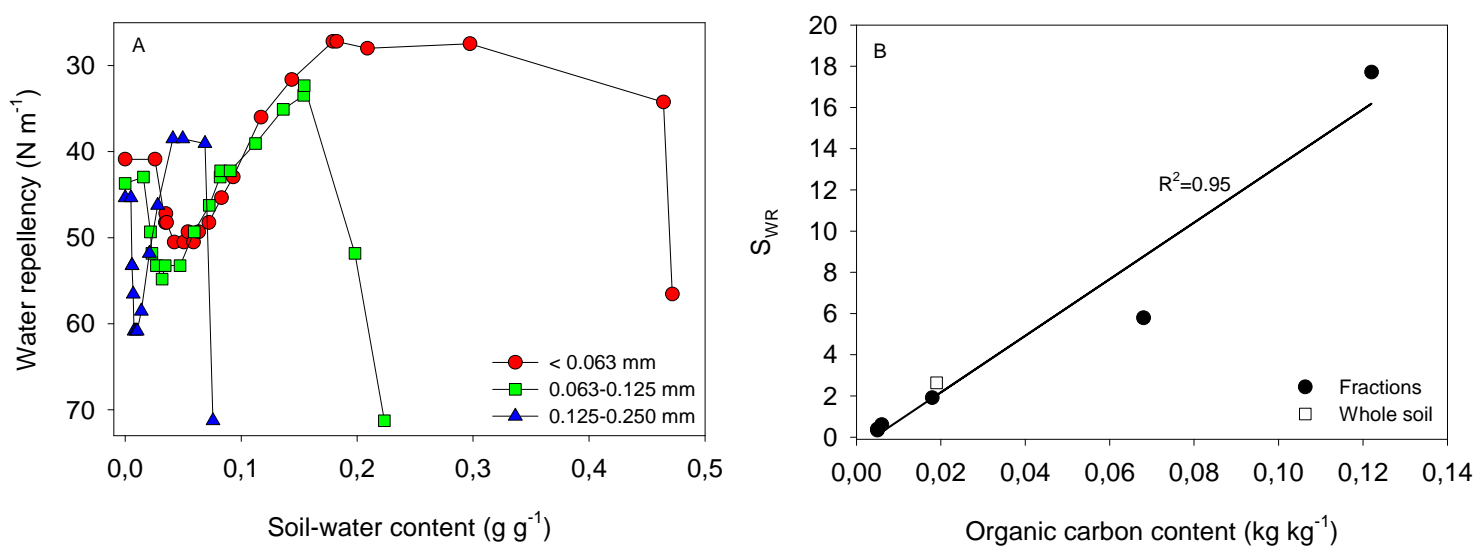

Fig. 10. (A) Soil water repellency as a function of soil-water content for three fractions of a Jyndevad soil. The trapezoidal integrated area under the curves $S_{W R}$ gives the overall degree of water repellency. (B) Plotting the trapezoidal integrated area in the WR-w curves, $S_{W R}$, against OC in the fractions as well as the whole soil shows that the OC content dominates the degree of water repellency.

\subsection{Sorption (partitioning) processes for organic chemicals}

Other important interface processes that are intimately linked to soil architecture (matrix and pore systems) and soil OM quality and quantity in combination with organo-clay complexing are sorption of organic vapors (Amali et al., 1994; Petersen et al., 1994, 1995) as well as dissolved chemicals (de Jonge et al., 2000, 2008). Taking a closer look at gaseous phase sorption in soils can lead to a renewed understanding of soil interface phenomena.

\subsubsection{Effects of soil moisture and matric potential}

Gaseous-phase sorption of non-polar chemicals are like WR highly dependent on soil-moisture conditions, likely making the chemical interface processes in soils highly complicated at the microscale and at present unpredictable at the pedon or larger scale. The WR-w curves for the Lundgaard and Ødum soils (marked in Fig. 11) are plotted together with curves relating gaseous phase sorption of the non-polar chemical trichloroethylene with $w$ (Fig. 12). The gaseous phase sorption at zero and very low soil moisture contents takes place directly at the mineral and organic surfaces. While soilwater contents increase, polar water molecules start competing with the non-polar TCE molecules for sorption sites. From oven-dry conditions to around soil-water contents of approximately four-five molecular layers the VOC adsorption capacity decreases non-linearly and drastically (Petersen et al., 1994, 1995) and Henry's Law is not valid. For this non-Henrian region the adsorption/dissolution (Eq. 9) is described by applying a solid/vapor adsorption coefficient, $K_{D}^{\prime}$ $\left(\mathrm{cm}^{3} \mathrm{~g}^{-1}\right)$, defined from:

$$
S_{S}+S_{w}=K_{D}^{\prime} C \rho_{b}
$$



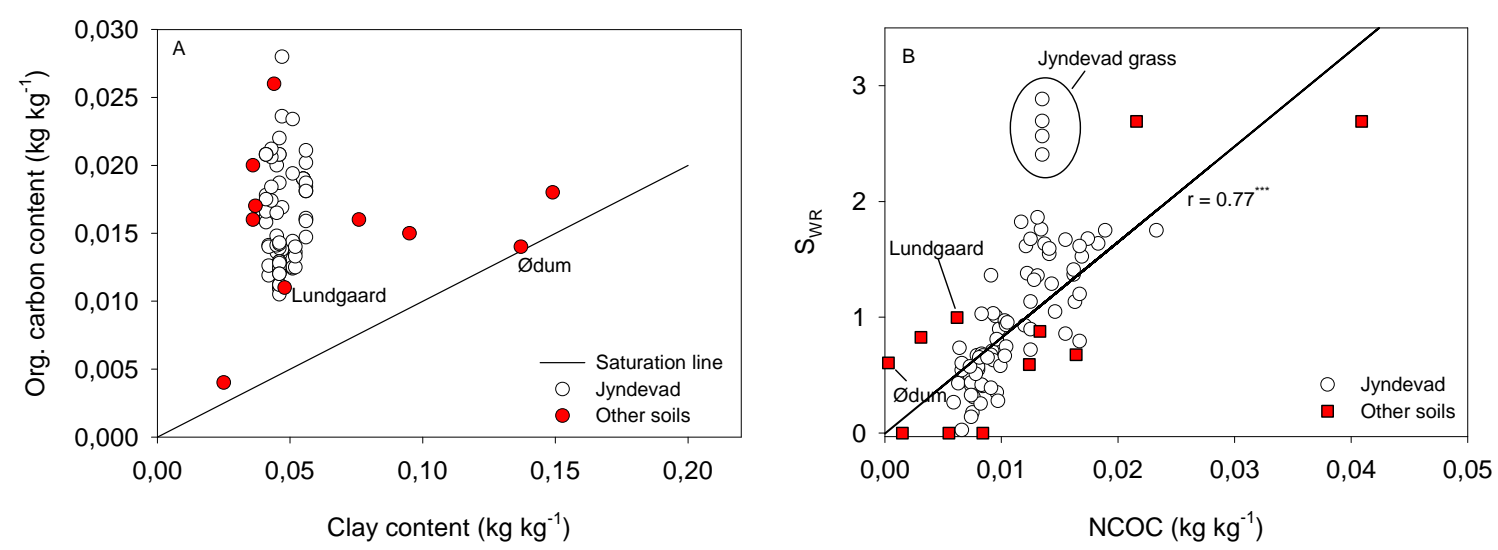

Fig. 11. (A) Relation between the content of clay and OC for numerous treatments of the Jyndevad soil (based on data from de Jonge et al., 2007) as well as 10 additional hydrophilic or hydrophobic soils (based on data from de Jonge et al., 1999). (B) The overall WR as determined by the trapezoidal integrated area under the WR-w curves as a function of non-complexed organic carbon (NCOC). The data are for the same soils as in panel (A).

where $S_{S}$ is the amount of VOC-vapor adsorbed to soil solids $\left(\mathrm{g} \mathrm{cm}^{-3}\right), S_{w}$ is VOC-vapor dissolved in water $\left(\mathrm{g} \mathrm{cm}^{-3}\right), \mathrm{C}$ is VOC concentration $\left(\mathrm{g} \mathrm{VOC} \mathrm{cm}{ }^{-3}\right)$, and $\rho_{b}$ is the bulk density $\left(\mathrm{g} \mathrm{cm}^{-3}\right)$. In the non-Henrian region between 0 and $\sim 4$ molecular layers of water coverage, the change in $K_{D}^{\prime}$ with changing water content can be predicted by Eq. (10):

$\log K_{D}^{\prime}=\left(A_{0}-\beta\right) e^{-\alpha w}+\beta$

where $A_{0}=\log K_{D}^{\prime}(w=0), \beta$ is a fitting parameter, and $\alpha$ as a function of $\beta$ is given by:

$\alpha=\frac{\ln \left(\frac{A_{4}-\beta}{A_{0}-\beta}\right)}{w_{4}}$

where $w_{4}$ is the water content at four molecular layers of water coverage, and $A_{4}=\log K_{D}^{\prime}\left(w_{4}\right)$. For soil-water contents higher than four molecular layers (Henrian region), the $\mathrm{K}^{\prime}{ }_{D}$ slightly increases with increasing water contents due to VOC dissolution into soil water. This phenomenon can be described by Eq. (12), assuming the applicability of Henry's Law and that water surface sorption and condensation are neglible, and corresponds to the linear parts of the $K_{D}^{\prime}-w$ curves (Fig. 12):

$K_{D}^{\prime}=\frac{K_{D}}{K_{H}}+\frac{w}{K_{H} \varphi \rho}$

where $K_{D}$ is the aqueous/solid partition coefficient $\left(\mathrm{cm}^{3} \mathrm{~g}^{-1}\right), K_{H}$ is Henry's constant, $\varphi$ is the aqueous activity coefficient $(=1)$, and $\rho$ is the density of water $\left(=1 \mathrm{~g} \mathrm{~cm}^{-3}\right)$.

When moving from the Non-Henry to the Henry region (Fig. 12) - around a molecular water coverage of 4-5, which is also being approximately equal to the wilting point - we seem to reach a crossroad in interface phenomena. The VOC vapour sorption reaches a minimum and around the same point the WR starts increasing. This corroborates with the hypothesis of Or et al. (2007) that partial water coverage of solids surfaces is one of the physical constraints/controls determining numerous interface processes. At the same time the geometry of the bound water (its distribution in films and pore throats) as well as the type of available surfaces (NC, $\mathrm{NCC}, \mathrm{COC}$, or NCOC) probably plays an important role regarding interface phenomena (Or et al., 2007; Dexter et al., 2008).

\subsubsection{Effects of soil matrix and clay saturation}

Surface area (total as, for example, estimated by EGME measurement or external as, for example, estimated by $\mathrm{N}_{2}$-BET) appears to be a key player in both vapor sorption and likely also WR, with surface areas of course being closely related to both OM and clay (the finer fractions of the soil matrix). For vapor sorption, clay mainly controls the dry region and OM the wet region. For WR, the interactions between OM and clay together with OM quality, control WR-w curve shape and magnitude. The analysis suggests that both the vapor sorption curve $\left(\mathrm{K}_{D}\right.$ '-w) and the WR curve (WR-w) may be key interface characteristics towards understanding soil architecture and functions.

The carbon saturation effect we take another closer look at with regard to sorption of the dissolved polycyclic aromatic hydrocarbons (PAH) pyrene and phenanthrene (Fig. 13). Generally PAHs adsorb strongly to the soil solid phase leaving them unavailable to leaching in the dissolved phase. Sorption coefficients of PAHs are frequently highly correlated to the soil OC (see reviews by Pignatello, 1998; Huang et al., 2003). The OC contents of eight European soils (de Jonge et al., 2008; Celis et al., 2006) are plotted as a function of their clay content (Fig. 14). The soils split into two groups with one above and one below the saturation line as defined by Dexter et al. (2008). The sorption coefficients, 
$K_{D}$, for pyrene and phenanthrene (de Jonge et al., 2008) are significantly correlated to the NCOC fraction of the soils as calculated by Eq. (8), and an improvement on the correlation to soil OC. The sorption coefficients are not correlated to the COC. Again, part of the OC pool seems to be mainly responsible for interface processes within soil inner space.

\section{Towards and beyond a road map for soil inner space}

Soil is the most complex biomaterial on the planet (Young and Crawford, 2004). If we look at soil inner space through a magnifying glass, it seems chaotic. At this scale, the natural intact soil represents an almost unimaginably complex architecture. At first glance, mineral particles, abiotic and biotic organic colloids, "colonies" of particles (aggregates) and biomass (films) appear connected in a random fashion. Constricted by this complicated architecture, water and numerous types of colloids, dissolved chemicals, air, and gaseous compounds move by tortuous routes. By their own translocation and ensuing biophysical processes, the mobile components are constantly changing soil architecture.

Understanding and navigating among the key parameters and processes in soil structure formation/breakdown and how they interactively affects translocations processes will require a scientific road map to soil inner space - or more likely a number of maps at different scales from nano over pedon to field. To effectively construct these maps so they are useful and accepted across soil, environmental, and hydrological sciences is a multidisciplinary effort. As a first step, a possible interpretation of soil inner space architecture and infrastructure in a map representing the smaller scale is given in Fig. 14. The map is the center part of Fig. 14, which again is part of maps of different scales and depending on e.g., soil spatial heterogeneity.

The pore and particle phases are sources of mobile soil constituents including gases, liquids, clay particles, and biotic and abiotic OM (Fig. 14). The mobile constituents travel along tortuous roads and highways formed by complex pore networks, while undergoing translocation processes such as diffusion, convection, dispersion, chemical sorption, and physical straining. External system inputs to soil architecture include management induced energy gradients, climateinduced gradients in moisture matric potential and temperature, and plant-root-induced exudates such as extracellular polymetric substances (EPS) working as biological glues in soil structure formation (Or et al., 2007) The external inputs interacting with the micro-scale biophysical processes cause a variety of not-yet-understood phenomena including creation/breakdown of aggregates, blocking of pore networks by deposited colloids, water repellency and onset of fingerlike water flow patterns, inter-connections of previously entrapped air-filled pore space, and onset of gas transport and dispersion. All these processes are intimately linked to the temporal and spatial dynamics of soil inner space architec-
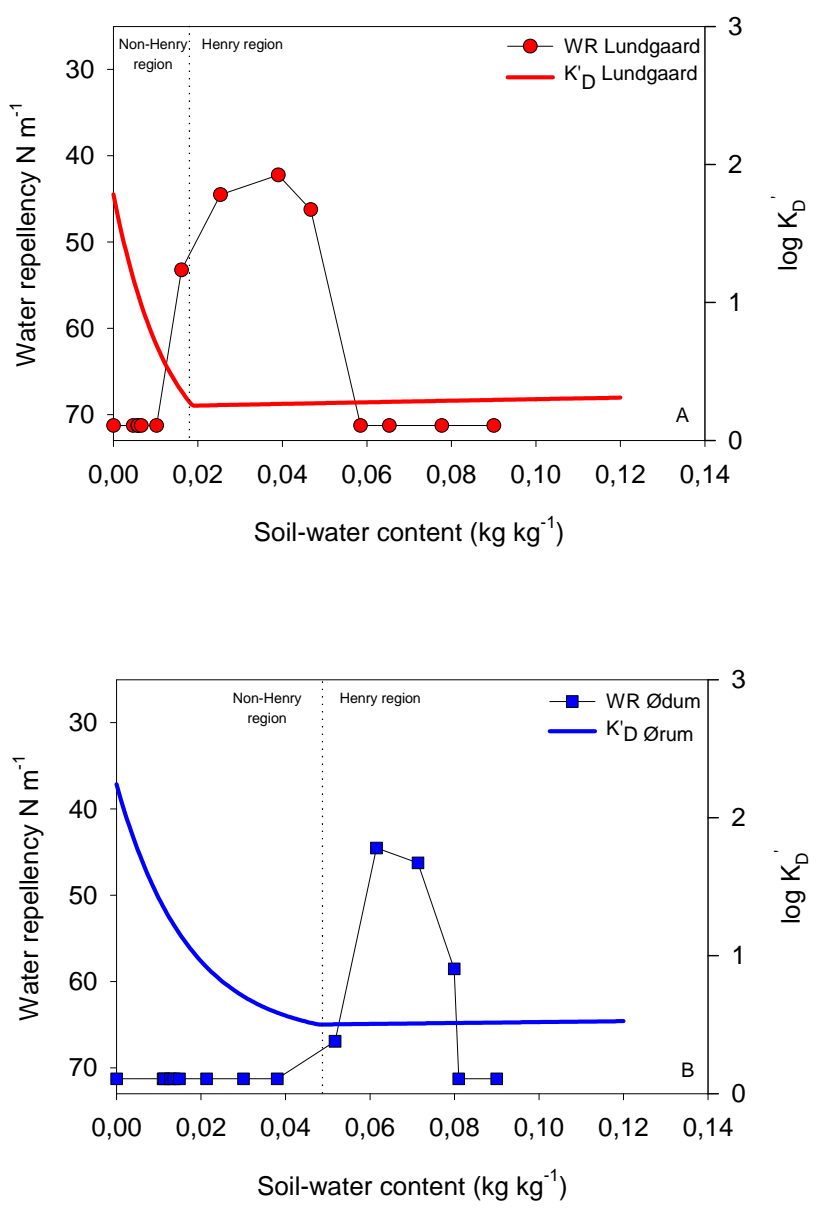

Fig. 12. Curves relating water repellency (WR) as well as gaseous phase TCE sorption $\left(K_{D}^{\prime}\right)$ to soil-water content for (A) Lundgaard (0.048 and $0.011 \mathrm{~kg} \mathrm{~kg}^{-1}$ clay and Org. C, respectively) and (B) Ødum (0.137 and $0.014 \mathrm{~kg} \mathrm{~kg}^{-1}$ clay and Org. C, respectively) soils. For gaseous phase sorption the sorption coefficient at low soil-water contents behaves in a non-Henryan way (the non-linear part of the curve), where gas molecules adsorb directly to mineral or organic surfaces or even bound water molecules. When there is sufficient water bound to the soil, the sorption coefficients can be predicted from Henry's Law and are dominated by partitioning from the water phase to sorption sites (the linear part of the curves).

ture, which in turn changes in constant interaction with the biophysical processes. New methods like computer tomography for more direct measurements of soil inner space can provide high resolution soil pore space images in 3-D and various pore structural parameters can be quantified from such images (see Taina et al., 2008, for a review) and aid in preparing road maps to inner space.

Based on the results from the present study, we suggest one interesting crossroad on the map is between the soilwater matric potential (moisture condition) and the Dexter et al. (2008) clay saturation line. The question arising at the crossroad is how a change in soil-water matric potential 

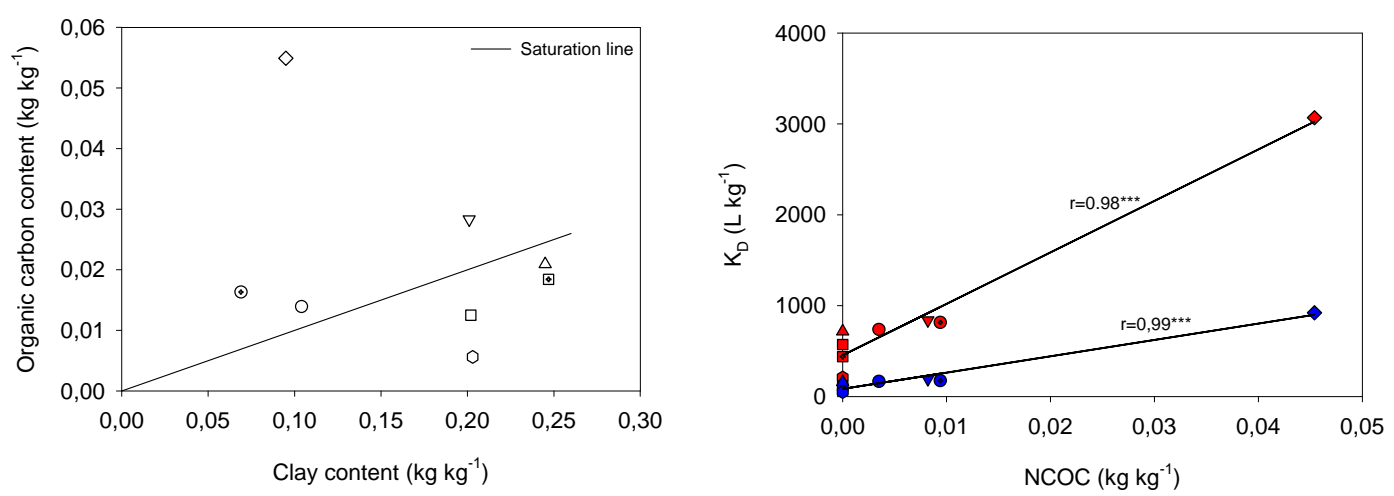

Fig. 13. (A) Relation between the content of clay and OC for eight European soils (modified after de Jonge et al., 2008). (B) The sorption coefficient of pyrene (red) and phenanthrene (blue) as a function of NCOC content in the soils.

will affect functional soil architecture depending on whether the local soil compartment is above or below the Dexter et al. (2008) clay saturation line. If there is a surplus of NCOC (Eqs. 3-4) and the water potential decreases below $-1000 \mathrm{hPa}(\mathrm{pF}>3)$, the analyses in this study would imply that water repellency, a more heterogeneous distribution of moisture on the micro-scale, and the occurrence of vapour sorption may be promoted. If instead there is a surplus of NCC (Eqs. 1-2), release and redistribution of water dispersible colloids (clay) may occur more easily. Any such threshold-induced change in soil infrastructure will both govern and, in turn, be affected by translocations of biotic and abiotic colloidal particles, water, solutes, air, and gases through phases and across interfaces and thus decide the overall soil functions and human and environmental impact.

The first draft of a "Road Map to soil inner space" and the first glance into the map - seeing the crossroad between moisture condition and clay saturation (clay-OC complexation) as one possible control of soil structure dynamics - is meant to fuel discussion and be an inspiration to revisit old data and look at new data in a fresh way, based on some of the emerging soil structure indexes such as the Dexter et al. (2008) clay saturation line. We hope such approaches can guide us forward to better understand and quantify irregular water flow and distribution, water repellency, preferential gas transport, chemical phase distribution at low-moisture conditions, colloid mobilization and colloid-facilitated transport, and ultimately identify key parameters and thresholds for formation of "healthy sponges" or "unhealthy pibes" (Fig. 7) and similar dramatic changes in functional soil architecture.

We realize that soil microbial and macro-biological parameters and their interactions play a key role in all of the above but have limited this study and the first glance on the road map (Fig. 14) to the more physical aspects of soil functional architecture. We have, though, added "soil microbial activity" to the map, since this is the driver behind soil architecture and soil self-organization. The ultimate vision behind and far beyond the Soil-it-is program is to collaborate across soil, environmental, and hydrological sciences towards understanding the controls and constraints of soil bio-physical interactions to enable us to predict changes in soil structure and functionality with time at different scales.

\section{Conclusions}

Conclusions that can be drawn on the preliminary results of the Soil-it-is project include:

- If carefully integrated and interpreted, multi-parameter measurements at scales from aggregates to minimally disturbed bulk soil samples $\left(100 \mathrm{~cm}^{3}\right.$ or larger) may provide valuable information of processes at a lower scale, although we acknowledge the great heterogeneity in soil architecture and processes at the colloid to cluster scale.

- Novel data analyses of soil-gas transport parameters are presented, including normalization of gas diffusivity data with regard to the water-induced linear reduction, WLR, model for structure-less porous media, and a Brooks-Corey power-law analysis taking into account a percolation threshold for gas diffusivity and introducing the ratio of intra- to inter-ped tortuosity-connectivity factors, $m$, as a useful indicator for characterizing porenetwork architecture.

- The new analyses supported a hypothesis of possible pipe-like pore network behavior for a soil below the Dexter et al. (2008) clay saturation line while an adjoining, differently managed soil of similar texture but placed above the clay saturation line exhibited a more sponge-like pore network behavior. The pipe-like pore structure of the low-C soil is seen as a result of dispersion-cementation cycles of clay not complexed by organic carbon (NCC), which is supported by high dispersibilities of field moist soil and high mechanical strengths of dry aggregates. 


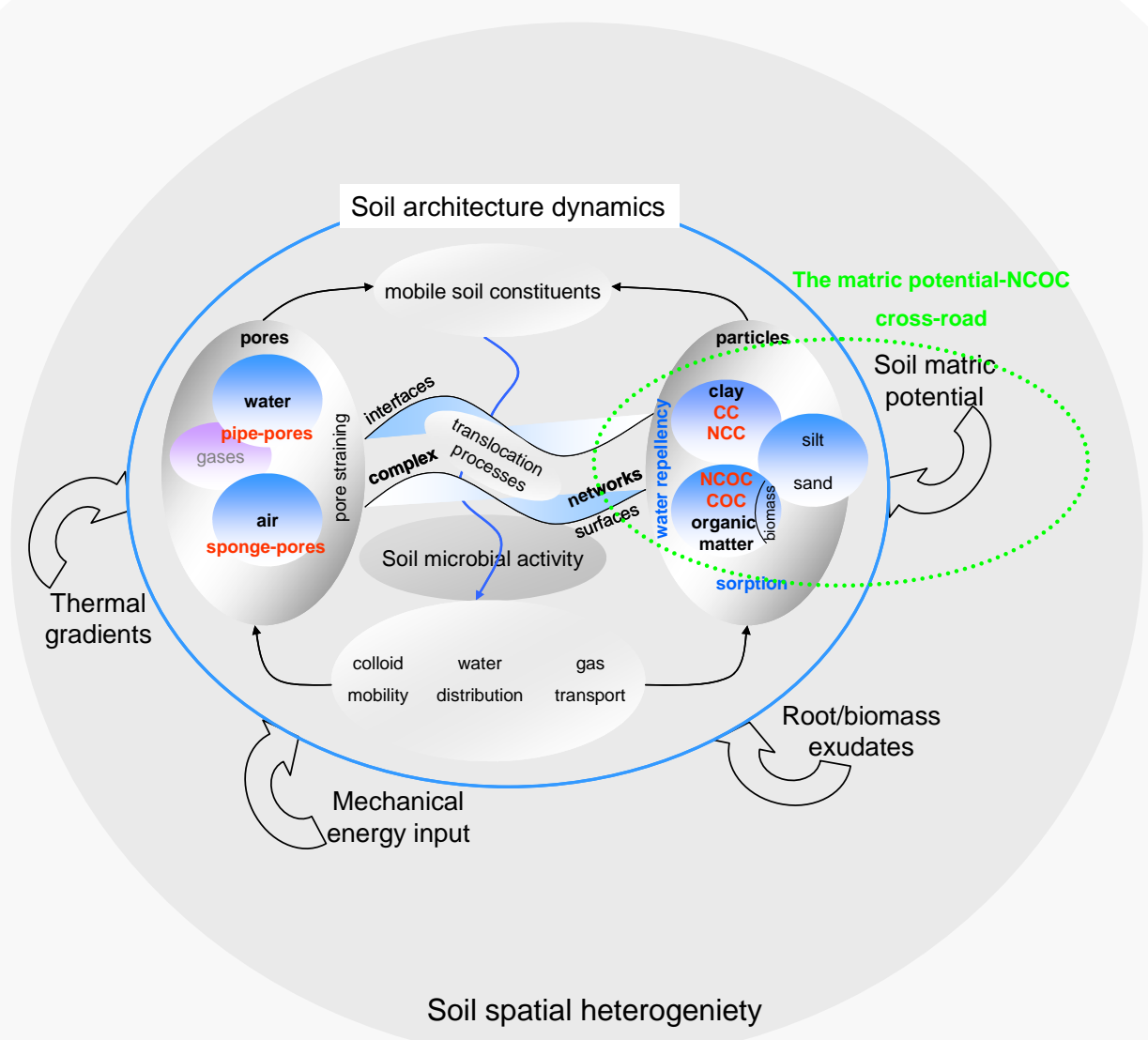

Soil scales and horizons

Fig. 14. Schematic road map to soil inner space and some not-yet-understood processes and phenomena. CC: Complexed clay, NCC: Non-complexed clay, COC: Complexed organic carbon, NCOC: Non-complexed organic carbon.

- The Dexter et al. (2008) clay saturation concept in combination with distribution and intensity of soil water may also in part govern functional soil architecture with regard to hydrological interface processes such as water repellency and fingered flow. For example, the area under the water repellency curve (water repellency versus gravimetric soil-water content) was positively correlated to non-complexed organic carbon (NCOC) for a number of differently textured and managed Danish soils.
- Also for interface processes governing the fate of environmental impact chemicals such as sorption of volatile organic chemicals and polycyclic aromatic hydrocarbons, PAHs, both NCOC and soil-moisture status were shown again to play a key role in the phase partitioning of both volatile vapors and PAHs.

- Based on these preliminary results, we envision a road map to soil inner space where important crossroads for key parameters (e.g. NCOC and soil-water matric potential) govern the build-up and resilience or breakdown 
of soil infrastructure and the thresholds for the ability of soils to self-organize after structure breakdown.

- The road map may hopefully serve as inspiration for a more focused and multi-disciplinary effort combining high-resolution measurement methods from soil sciences, hydropedology and engineering disciplines in soil inner space.

Acknowledgements. This work was financed by the international project Soil Infrastructure, Interfaces, and Translocation Processes in Inner Space (Soil-it-is) granted by the Danish Research Council for Technology and Production Sciences www.agrsci.dk/soil-it-is/.

Edited by: H. Lin

\section{References}

Amali, S., Petersen, L. W., Rolston, D. E., and Moldrup, P.: Modeling multicomponent volatile organic and water vapor adsorption on soils, J. Hazard. Mat., 36, 89-108, 1994.

Ball, B. C.: Modelling of soil pores as tubes using gas permeabilities, gas diffusivities and water release, J. Soil Sci., 32, 465-481, 1981.

Bradford, S. A. and Torkzaban, S.: Colloid transport and retention in unsaturated porous media: A review of interface-, collector-, and pore-scale processes and models, Vadose Zone J., 7, 667681, 2008.

Brooks, R. H. and Corey, A. T.: Properties of porous media affecting fluid flow, J. Irrig. Drain. Eng. Div. Am. Soc. Civ. Eng. (ASCE), 92, 61-89, 1966.

Carter, M. R., Angers, D. A., Gregorich, E. G., and Bolinder, M. A.: Characterizing organic matter retention for surface soils in eastern Canada using density and particle size fractions, Can. J. Soil Sci., 83, 11-23, 2003.

Celis, R., de Jonge, H., de Jonge, L. W., Real, M., Hermosin, M. C., and Cornejo, J.: The role of mineral and organic components in phenanthrene and dibenzofuran sorption by soil, Eur. J. Soil Sci., 57, 308-319, 2006.

Czy, E. A., Dexter, A. R., and Terelak, H.: Content of readilydispersible clay in the arable layer of some Polish soils, in: Sustainable Land Management-Environmental Protection, edited by: Pagliai, M. and Jones, R., Adv. Geoecology, 35, 115-124, 2002.

de Jonge, L. W., Jacobsen, O. H., and Moldrup, P.: Soil waterrepellency: Effects of water content, temperature, and particle size, Soil Sci. Soc. Am. J., 63, 437-442, 1999.

de Jonge, L. W., de Jonge, H., Moldrup, P., Jacobsen, O. H., and Christensen, B. T.: Sorption of Prochloraz on primary soil organomineral size separates, J. Environ. Qual., 29, 206-213, 2000 .

de Jonge, L. W., Kjaergaard, C., and Moldrup, P.: Colloids and colloid-facilitated transport of contaminants in soils: An introduction, Vadose Zone J., 3, 321-325, 2004a.

de Jonge, L. W., Moldrup, P., Rubæk, G. H., Schelde, K., and Djurhuus, J.: Particle leaching and particle-facilitated transport of phosphorus at field scale, Vadose Zone J., 3, 462-470, 2004b.

de Jonge, L. W., Moldrup, P., and Jacobsen, O. H.: Soil-water content dependency of water repellency in soils: Effect of crop type, soil management, and physical-chemical parameters, Soil Sci., 172, 577-588, 2007.

de Jonge, L. W., Moldrup, P., de Jonge, H., and Celis, R.: Sorption and leaching of short-term-aged PAHs in eight European Soils: Link to physical-chemical properties and leaching of dissolved organic carbon, Soil Sci., 173, 13-24, 2008.

Denef, K. and Six, J.: Clay mineralogy determines the importance of biological versus abiotic processes for macroaggregate formation and stabilization, Eur. J. Soil Sci., 56, 469-479, 2005.

Dexter, A. R.: Advances in characterization of soil structure, Soil Till. Res., 63, 199-238, 1988.

Dexter, A. R., Richard, G., Arrouays, D., Czyz, E. A., Jolivet, C., and Duval, O.: Complexed organic matter controls soil physical properties, Geoderma, 144, 620-627, 2008.

Elmholt, S., Schjønning, P., Munkholm, L. J., and Debosz, K.: Soil management effects on aggregate stability and biological binding, Geoderma, 144, 455-467, 2008.

Groenevelt, P. H., Kay, B. D., and Grant, C. D.: Physical assessment of a soil with respect to rooting potential, Geoderma, 34, 101114, 1984.

Håkansson, I.: A method for characterizing the state of compactness of the plough layer, Soil Till. Res., 16, 105-120, 1990.

Hallett, P. D. and Young, I. M.: Changes to water repellency of soil aggregates caused by substrate-induced microbial activity, Eur. J. Soil Sci., 50, 35-40, 1999.

Hallett, P. D., Baumgartl, T., and Young, I. M.: Subcritical water repellency of aggregates from a range of soil management practices, Soil Sci. Soc. Am. J., 65, 184-190, 2001.

Hallett, P. D., Nunan, N., Douglas, J. T., and Young, I. M.: Milimeter-scale spatial variability in soil-water sorptivity: Scale, surface elevation, and subcritical repellency effects, Soil Sci. Soc. Am. J., 68, 352-358, 2004.

Hassink, J.: The capacity of soils to preserve organic $\mathrm{C}$ and $\mathrm{N}$ by their association with clay and silt particles, Plant and Soil, 191, 77-87, 1997.

Heylighen, F.: The Science of self-organization and adaptivity, in: Knowledge Management, Organizational Intelligence and Learning, and Complexity, edited by: Kiel, L. D., in: The Encyclopedia of Life Support Systems ((EOLSS), Eolss Publishers, Oxford, 2001.

Holling, C. S.: Resilience and stability of ecological systems, Annu. Rev. Ecol. Systematics, 4, 1-23, 1973.

Huang, W., Peng, P., Yu, Z., and Fu, J.: Effects of organic matter heterogeneity on sorption and desorption of organic contaminants by soils and sediments, Appl. Geochemistry, 18, 955-972, 2003.

Hunt, A. G.: Percolation theory for flow in porous media, SpringerVerlag, Berlin, 2005.

Ingram, J. S. I. and Fernandes, E. C. M.:Managing carbon sequestration in soils: concepts and terminology, Agriculture, Ecosystems and Environment 87, 111-117, 2001.

Kawamoto, K., Moldrup, P., Komatsu, T., de Jonge, L. W., and Oda, M.: Water repellency of aggregate size fractions of a volcanic ash soil, Soil Sci. Soc. Am. J., 71, 1658-1666, 2007.

Kemper, W. D., Rosenau, R. C., and Dexter, A. R.: Cohesion development in disrupted soils as affected by clay and organic matter content and temperature, Soil Sci. Soc. Am. J., 51, 860-867, 1987.

King, P. M.: Comparison of methods for measuring severity of wa- 
ter repellence of sandy soils and assessment of some factors that affect its measurement, Aust. J. Soil Res., 19, 275-285, 1981.

Kjaergaard, C., de Jonge, L. W., Moldrup, P., and Schjønning, P.: Water-dispersible colloids: Effects of measurement method, clay content, initial soil matric potential and wetting rate, Vadose Zone J., 3, 403-412, 2004.

Mayer, L. M. and Xing, B.: Organic matter - surface area relationships in acid soils, Soil Sci. Soc. Am. J., 65, 250-258, 2001.

McHale, G., Shirtcliffe, N. J., Newton, M. I., and Pyatt, F. B.: Selforganization of hydrophobic soil and granular surfaces, Appl. Phys. Lett., 90, 541101-541103, 2007.

Moldrup, P., Olesen, T., Gamst, J., Yamaguchi, T., and Rolston, D. E.: Predicting the gas diffusion coefficient in repacked soil: Water-induced linear reduction model, Soil Sci. Soc. Am. J., 64, 1588-1594, 2000.

Moldrup, P., Olesen, T., Komatsu, T., Schjønning, P., and Rolston, D. E.: Tortuosity, diffusivity, and permeability in the soil liquid and gaseous phases, Soil Sci. Soc. Am. J., 65, 613-623, 2001.

Moldrup, P., Yoshikawa, S., Olesen, T., Komatsu, T., and Rolston, D. E.: Gas diffusivity in undisturbed volcanic ash soils: Test of soil-water-characteristic-based prediction models, Soil Sci. Soc. Am. J., 67, 41-51, 2003a.

Moldrup, P., Yoshikawa, S., Olesen, T., Komatsu, T., and Rolston, D. E.: Air permeability in undisturbed volcanic ash soils: Predictive model test and soil structure fingerprint, Soil Sci. Soc. Am. J., 67, 32-40, 2003b.

Moldrup, P., Olesen, T., Yoshikawa, S., Komatsu, T., and Rolston, D. E.: Three-porosity model for predicting the gas diffusion coefficient in undisturbed soil, Soil Sci. Soc. Am. J., 68, 750-759, 2004.

Molope, M. B., Page, E. R., and Grieve, I. C.: A comparison of soil aggregate stability tests using soils with contrasting cultivation histories, Commun. Soil Sci. Plant Anal., 16, 315-322, 1985.

Mullins, C. E., Young, I. M., Bengough, A. G., and Ley, G. J.: Hard-Setting Soils, Soil Use Manag., 3, 79-83, 1987.

Munkholm, L. J., Schjønning, P., Debosz, K., Jensen, H. E., and Christensen, B. T.: Aggregate strength and mechanical behaviour of a sandy loam under long-term fertilization treatments, Eur. J. Soil Sci., 53, 129-137, 2002.

Munkholm, L. J., Schjønning, P., and Petersen, C. T.: Soil mechanical behaviour of sandy loams in a temperate climate: case-studies on long-term effects of fertilization and crop rotation, Soil Use Manag., 17, 269-277, 2001.

Nissen, H. H., Moldrup, P., de Jonge, L. W., and Jacobsen, O. H.: Time domain reflectometry coil probe measurements of water content during fingered flow, Soil Sci. Soc. Am. J., 63, 493-500, 1999.

NRC: Basic research opportunities in earth science, National Academy Press, Washington, D.C., 2001.

Or, D., Smets, B. F., Wraith, J. M., Dechesne, A., and Friedman, S. P.: Physical constraints affecting bacterial habitats and activity in unsaturated porous media - a review, Adv. Water Res., 30, 1505-1527, 2007.

Petersen, L. W., Rolston, D. E., Moldrup, P., and Yamaguchi, T.: Volatile organic vapor diffusion and adsorption in soils, J. Environ. Qual., 23, 799-805, 1994.

Petersen, L. W., Moldrup, P., El-Farhan, Y. H., Jacobsen, O. H., Yamaguchi, T., and Rolston, D. E.: Effects of moisture and soil texture on the adsorption of organic vapors, J. Environ. Qual., 24,
752-759, 1995.

Pignatello, J. J.: Soil organic matter as a nanoporous sorbent of organic pollutants, Adv. Colloid Interfase Sci., 77, 445-467, 1998.

Pojasok, T. and Kay, B. D.: Assessment of a combination of wet sieving and turbidimetry to characterize the structural stability of moist aggregates, Can J. Soil Sci., 70, 33-42, 1990.

Poulsen, T. G., Moldrup, P., de Jonge, L. W., and Komatsu, T.: Colloid and bromide transport in undisturbed soil columns: Application of two-region model, Vadose Zone J., 5, 649-656, 2006.

Regalado, C. M., Ritter, A., de Jonge, L. W., Kawamoto, K., Komatsu, T., and Moldrup, P.: Useful soil-water repellency indices: Linear correlations, Soil Sci., 173, 747-757, 2008.

Robinson, D. A., Lebron, I., and Vereecken, H.: On the definition of the natural capital of soils: A framework for description, evaluation and monitoring, Soil Sci. Soc. Am. J., in press, 2009.

Schjønning, P., Christensen, B. T., and Carstensen, B.: Physical and chemical properties of a sandy loam receiving animal manure, mineral fertilizer or no fertilizer for 90 years, Eur. J. Soil Sci., 45, 257-268, 1994.

Schjønning, P., Elmholt, S., Munkholm, L. J., and Debosz, K.: Soil quality aspects of humid sandy loams as influenced by different long-term management, Agriculture, Ecosystems and Environment, 88, 195-214, 2002a.

Schjønning, P., Munkholm, L. J., Moldrup, P., and Jacobsen, O. H.: Modelling soil pore characteristics from measurements of air exchange: the long-term effects of fertilization and crop rotation, Eur. J. Soil Sci., 53, 331-339, 2002b.

Sen, T. K. and Khilar, K. C.: Review on subsurface colloids and colloid-associated contaminant transport in saturated porous media, Adv. Coll. Interface Sci., 119, 71-96, 2006.

Skopp, J., Jawson, M. D., and Doran, J. W.: Steady-state aerobic microbial activity as a function of soil-water content, Soil Sci. Soc. Am. J., 54, 1619-1625, 1990.

Swift, M. J.: Maintaining the biological status of soil: a key to sustainable land management?, in: Soil resilience and Sustainable Land Use, edited by: Greenland, D. J. and Szabolcs, I., CAB International, Wallingford, UK, pp. 235-247, 1994.

Taina, I. A., Heck, R. J., and Elliot, T. R.: Application of X-ray computed tomography to soil science: A literature review, Can. J. Soil Sci., 88, 1-20, 2008.

Tisdall, J. M. and Oades, J. M.: Organic matter and water stable aggregates in soils, J. Soil Sci., 33, 141-164, 1982.

Utomo, W. H. and Dexter, A. R.: Soil friability, J. Soil Sci., 32, 203-213, 1981.

Vogel, H.-J. and Babel, U.: Soil space diversity and its dynamics: Qualitative and quantitative considerations, in: Biodiversity in agricultural production systems, edited by: Benkiser, G., and Schnell, S., CRC Press Inc, 2006.

Wallis, M. G., Horne, D. J., and McAuliffe, K. W.: A study of water repellency and its amelioration in a yellow-brown sand. 2 . Use of wetting agents and their interaction with some aspects of irrigation, N.Z. J. Agr. Res., 33, 145-150, 1990.

Wallis, M. G., Scotter, D. R., and Horne, D. J.: An evaluation of the intrinsic sorptivity water repellency index on a range of New Zealand soils, Aust. J. Soil Res., 29, 353-362, 1991.

Watts, C. W. and Dexter, A. R.: The influence of organic matter in reducing the destabilization of soil by simulated tillage, Soil Tillage Research, 42, 253-275, 1997.

Watts, C. W. and Dexter, A. R.: Soil friability: theory, measure- 
ment and the effects of management and organic carbon content, European J. Soil Sci., 49, 73-84, 1998.

Weast, R. C., Astle, M. J., and Beyer, W. H. (Eds.): CRC Handbook of Chemistry and Physics, 64th edn. CRC Press, Boca Raton, FL, 1983.
Williams, B. G., Greenland, D. J., Lindstrom, G. R., and Quirk, J. P.: Techniques for the determination of the stability of soil aggregates, Soil Sci., 101, 157-163, 1966.

Young, I. M. and Crawford, J. W.: Soils - The final frontier. Review paper: Interactions and self-organization in the soil-microbe complex, Science, 304, 1634-1637, 2004. 